\title{
The Association Between Pre-pregnancy BMI and Preterm Delivery in a Diverse Southern California Population of Working Women
}

\author{
Jessica Lang Kosa $\cdot$ Sylvia Guendelman • \\ Michelle Pearl - Steve Graham • \\ Barbara Abrams • Martin Kharrazi
}

Published online: 3 July 2010

(c) The Author(s) 2010. This article is published with open access at Springerlink.com

\begin{abstract}
Whereas preterm birth has consistently been associated with low maternal pre-pregnancy weight, the relationship with high pre-pregnancy weight has been inconsistent. We quantified the pre-pregnancy BMI-preterm delivery (PTD) relationship using traditional BMI categories (underweight, normal weight, overweight and obese) as well as continuous BMI. Eligible women participated in California's statewide prenatal screening program, worked during pregnancy, and delivered a live singleton birth in Southern California in 2002-2003. The final analytic sample included 354 cases delivering at $<37$ weeks, as identified by clinical estimate of gestational age from screening records, and 710 term normal-birthweight controls. Multivariable logistic regression models using categorical BMI levels and continuous BMI were compared. In categorical analyses, PTD was significantly associated with pre-pregnancy underweight only. Nonparametric local regression revealed a $\mathrm{V}$-shaped relationship between continuous BMI and PTD, with minimum risk at the high end of normal, around $24 \mathrm{~kg} / \mathrm{m}^{2}$. The odds ratio (OR) for PTD associated with low BMI within the normal range $\left(19 \mathrm{~kg} / \mathrm{m}^{2}\right)$ was $2.84(95 \% \mathrm{CI}=1.61-5.01)$; ORs for higher BMI in the overweight $\left(29 \mathrm{~kg} / \mathrm{m}^{2}\right)$ and obese $\left(34 \mathrm{~kg} / \mathrm{m}^{2}\right)$ ranges were $1.42(95 \% \mathrm{CI}=1.10-1.84)$
\end{abstract}

\footnotetext{
J. L. Kosa · S. Guendelman ( $₫) \cdot$ B. Abrams

Maternal and Child Health Program, School of Public Health, University of California, 207 J University Hall, Berkeley, CA 94720-7360, USA

e-mail: sylviag@berkeley.edu

M. Pearl · S. Graham

Sequoia Foundation, Richmond, CA, USA

M. Kharrazi

California Department of Public Health, Richmond, CA, USA
}

and 2.01 (95\% CI $=1.20-3.39)$ respectively, relative to $24 \mathrm{~kg} / \mathrm{m}^{2}$ ). BMI categories obscured the preterm delivery risk associated with low-normal, overweight, and obese BMI. We found that higher BMI up to around $24 \mathrm{~kg} / \mathrm{m}^{2}$ is increasingly protective of preterm delivery, beyond which a higher body mass index becomes detrimental. Current NHLBI/WHO BMI categories may be inadequate for identifying women at higher risk for PTD.

Keywords Obesity · BMI - Preterm delivery · Pre-conception

\section{Introduction}

The weight at which women begin their pregnancies can affect their outcomes and those of their infants. In the US, $26 \%$ of non-pregnant women 20-39 years of age are overweight (defined as a body mass index [BMI] of $25-29.9 \mathrm{~kg} / \mathrm{m}^{2}$ ), 29\% are obese (BMI $30-39.9 \mathrm{~kg} / \mathrm{m}^{2}$ ) and an additional $8 \%$ are morbidly obese (BMI $\geq 40 \mathrm{~kg} / \mathrm{m}^{2}$ ). Such high prevalence of overweight and obesity among childbearing women is a major public health concern given its contribution to pregnancy complications including gestational diabetes, gestational hypertension, pre-eclampsia, fetal macrosomia, and cesarean delivery.

Preterm delivery (PTD), defined as birth at less than 37 weeks gestation, has long been a known consequence of maternal underweight [1], but less than $3 \%$ of Americans aged 20-39 are underweight (BMI < 18.5). Pre-pregnancy obesity has also been associated with PTD in some but not all studies [2-7]. Cnattingius [4] found an increased risk specifically among nulliparous obese women. Weiss et al. [6] and Callaway et al. reported a significantly elevated risk of PTD among the morbidly obese only. Baeten et al. [12] 
found that obesity had a stronger association with early preterm birth ( $<32$ weeks) than overall preterm birth. By contrast, Sebire [7], and Kumari [8] did not find a significantly increased risk of PTD associated with maternal obesity in their patient populations, and Khashan identified a protective effect of overweight and obesity against PTD [1].

Differences in study populations and varying definitions of both PTD and obesity likely contribute to inconsistent findings. All of the abovementioned studies categorized BMI, most using the NHLBI/WHO definitions of underweight, normal weight, overweight, and obese [9, 10] adopted in 1995 based on mortality studies [11]. Treating pre-pregnancy BMI in this fashion implicitly models the increase in PTD risk as a stepwise function, with risk constant within each category, and then increasing abruptly at the category boundary. This assumption may not adequately approximate the actual shape of the risk distribution. Of particular concern is that the "normal" category used as a reference group represents a wide range of weight-for-height, and any heterogeneity in risk within the reference group can mask an association of pre-pregnancy BMI and outcome.

Two recent studies examined continuous pre-pregnancy BMI and found increased PTD risk with decreasing BMI below 22-26 kg/m², suggesting differences in PTD risk within the category traditionally defined as "normal weight"[20, 21]. Neither study found a significant increase in PTD associated with higher BMI. However, one study limited preterm births to spontaneous deliveries before 36 weeks, and the other relied upon last menstrual period to determine gestational age and included very few PTD cases with $\mathrm{BMI}>25$.

Given rising rates of PTD and obesity in the United States, even a small increase in risk would affect a large number of women. Therefore, it is important to understand whether pre-pregnancy overweight and obesity contribute to PTD, and if so, to identify the BMI level at which the risk of PTD begins to increase. This paper investigates these associations in a diverse population of working women who delivered preterm and term, normal-weight infants. We compare results using the NHLBI/WHO categories to models using continuous BMI to determine whether BMI categories are adequately characterizing the exposure-response relationship.

\section{Materials and Methods}

Participants were from a nested, population-based casecontrol study, Juggling Work and Life During Pregnancy, designed to examine the relationship between maternity leave, stress and pregnancy outcomes [22]. Eligible women participated in the California Department of Public Health's mid-trimester Prenatal Screening Program (PNS) in three Southern California counties (Orange, Imperial and San Diego); delivered live births between July 2002 and December 2003; were at least 18 years old; had a singleton birth without congenital anomalies, and had a US mailing address, yielding 38,278 women with linked data (Fig. 1). Sampled women included all women delivering either preterm (PTD) or low-birthweight (LBW) infants $(n=$ 3,357 ) according to last menstrual period and birthweight from birth records registered between July 2002 and August 2003; a random sample of controls delivering normal weight at term ( $\geq 2,500 \mathrm{~g}$ and $\geq 37$ weeks gestation) frequency matched on race and month-of-birth $(n=3,367)$; and an additional 504 PTD/LBW cases delivering between September and December of 2003, as described previously $[12,13]$. Sampled potential participants were mailed an introductory letter and subsequently prescreened by telephone to ascertain that they had worked $20 \mathrm{~h}$ or more per week during the first two trimesters of pregnancy or through the date of PNS. Details of the 45-min telephone interview have been described elsewhere [13]. Overall, 1,214 women who worked at least $20 \mathrm{~h} /$ week through the date of prenatal screening completed interviews. Because most refusals occurred before work eligibility could be determined, the number of refusals among eligible women was estimated by multiplying the number of refusals $(n=740)$ by the eligibility rate $(45 \%)$. Incomplete interviews $(n=109)$ were treated as refusals to eligible women, yielding an imputed refusal rate of $27 \%$ among eligible women contacted for the study $((.45 \times 740+109) /(.45 \times 740+109+1,214))$. Eligibility and refusal rates were the same for women delivering cases and controls. Mean and median interview time after birth was 4.5 months in cases and controls. Bilingual Spanish-English interviewers used CATI (Computer Assisted Telephone Interviewing) software to enter the responses into a database and offered $\$ 10$ gift cards to participants in return for a completed interview.

For analysis, gestational age at delivery was derived from the best clinical estimate recorded in PNS records. Gestational age estimates from PNS records have been shown to be superior to LMP-based gestational age from birth records [14, 15]. Sixty-two percent of study records had gestational age based on first trimester ultrasound, $34.5 \%$ on LMP dates, and $3.5 \%$ on physical exam. Women delivering term LBW infants $(n=82)$ were excluded from this analysis of preterm delivery. Women reporting births with congenital anomalies during the interview $(n=38)$, or for whom BMI was not available $(n=30)$ were also excluded, leaving a final sample of 354 PTD cases and 710 term, non-LBW controls.

The study protocol was approved by the Committees for the Protection of Human Subjects at the University of 


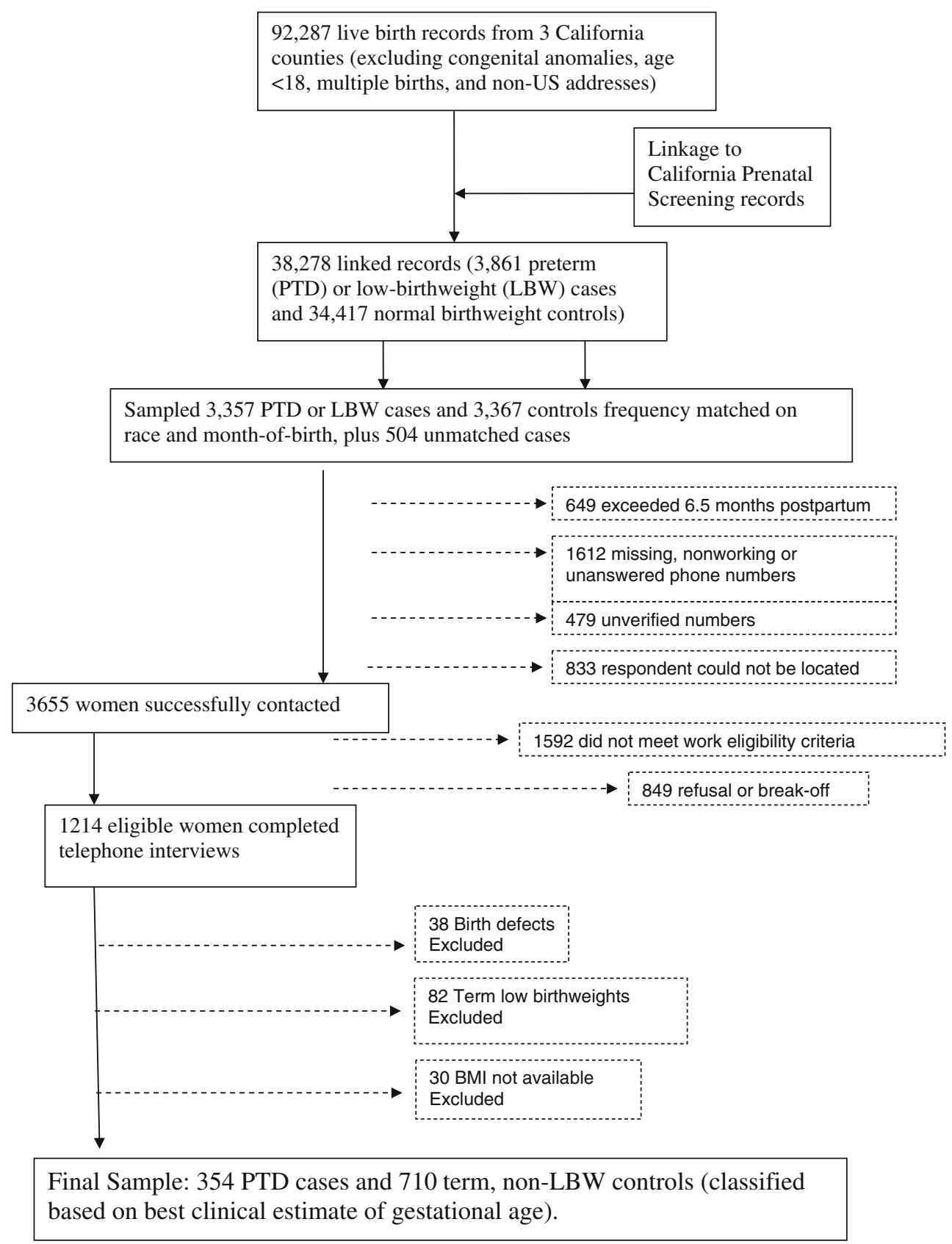

Fig. 1 Flow chart of exclusion criteria

California, Berkeley (No. 2003-5-115) and at the California Health and Human Services Agency (No. 02-10-18).

\section{Measures and Data Collection Instruments}

The key exposure was pre-pregnancy BMI, calculated from height and pre-pregnancy weight as reported in the survey. It was categorized as underweight $\left(<18.5 \mathrm{~kg} / \mathrm{m}^{2}\right)$, normal $\left(\mathrm{BMI}=18.5-<25 \mathrm{~kg} / \mathrm{m}^{2}\right)$, overweight $(\mathrm{BMI}=$ $25-<30 \mathrm{~kg} / \mathrm{m}^{2}$ ) and obese $\left(\right.$ BMI $\geq 30 \mathrm{~kg} / \mathrm{m}^{2}$ ) following NHLBI/WHO guidelines [9, 10], and also as a continuous variable. Self-reported pre-pregnancy weight was highly correlated with clinically measured weight at the time of prenatal screening in the second trimester (Pearson's $r=0.91$ among controls, 0.93 among cases).

Several other variables obtained from the telephone interview were considered. Psychosocial stress refers to distress from acute life events during pregnancy, measured by the Life Events Inventory modified for use with pregnant populations [16] Health variables during pregnancy included self-reported maternal smoking, diabetes (gestational and pre-existing), and averaging less than $6 \mathrm{~h}$ 
of sleep per night. Weight gain during pregnancy was calculated from self-reported pre-pregnancy weight and weight at delivery. Because shorter pregnancies provide less opportunity for weight gain, rate of gain $(\mathrm{kg} / \mathrm{week})$ was calculated as self-reported weight gained during pregnancy, divided by weeks gestation (LMP gestational age-2 weeks), and classified as low $(<0.27 \mathrm{~kg} /$ week $)$, adequate $(0.27-0.52 \mathrm{~kg} /$ week), or high $(>0.52 \mathrm{~kg} /$ week). This represents an average rate of gain over the duration of the pregnancy, and has been previously shown to predict PTD [17]. Socio-demographic variables were: maternal age, race/ethnicity, parity and highest educational attainment at time of delivery; annual household income; and marital/cohabiting status.

\section{Data Analysis}

All analyses were performed using SAS version 9.2 (SAS Institute, Inc., North Carolina). Cases and controls were compared on their socio-demographic and health characteristics, and $P$-values for comparisons were obtained from logistic regression models adjusting for frequency matching on race and birth month. Multiple logistic regression models were used to test whether BMI, treated as a categorical variable, predicted PTD after adjustment for potential confounders. To avoid excessive influence by outliers, the top and bottom $1 \%$ of BMI values were excluded from the models $(n=20)$. All models were also tested with these outliers included. Covariates were included in the model if associated with the outcome at $P \leq 0.10$ in bivariate analyses. Diabetes was not included as a covariate due to the likelihood of its being on the causal pathway. Instead, odds ratios were calculated including and excluding women with diabetes. Height was tested as a covariate in each model but did not alter odds ratios by $10 \%$. To account for frequency matching in the case-control design, odds ratios along with 95\% confidence intervals (CI) were adjusted for race and month of birth.

The shape of the BMI-PTD relationship was investigated using BMI as a continuous variable. Locally weighted scatter plot smoothing (LOESS) was used to explore and plot the shape of the BMI-PTD relationship without parametric assumptions [18]. LOESS curves were generated with and without adjustment for race, separately for the two largest ethnic groups (White and Latina), and stratified by parity.

Based on the shape of the LOESS plot, BMI was modeled as two linear functions, one equal to or below and one above the inflexion point $\left(\mathrm{BMI}=24 \mathrm{~kg} / \mathrm{m}^{2}\right)$. The slopes from these two logistic models were used to calculate odds ratios and $95 \%$ CIs for selected BMI values, with $24 \mathrm{~kg} / \mathrm{m}^{2}$ as the reference point. Potential confounders and adjustments for study design were included as described above.

\section{Results}

Characteristics Associated with Pre-Term Delivery in the Study Population

Women delivering preterm were more likely to be primiparous, single, to sleep on average less than $6 \mathrm{~h} / \mathrm{hight}$ during pregnancy, to have high $(>0.52 \mathrm{~kg} /$ week) or low $(<0.27 \mathrm{~kg} /$ week) weight gain during pregnancy, and to report diabetes (Table 1). They were also more likely than controls to be obese or underweight prior to pregnancy, though the association with obesity was marginally significant $(P=0.06)$.

\section{The Association of Pre-pregnancy BMI Categories} and PTD

Compared to women with a normal pre-pregnancy BMI, women who were underweight had over twice the odds of PTD $(\mathrm{AOR}=2.11(95 \% \mathrm{CI}=1.03-4.32)$ after adjusting for race, birth month, parity, marital status, nightly sleep hours and weight gain during pregnancy (Table 2). Neither overweight nor obesity was significantly associated with increased odds of PTD after adjustment for potential confounders. Inclusion of subjects with BMI in the top $1 \%$ $\left(>43 \mathrm{~kg} / \mathrm{m}^{2}\right)$ and bottom $1 \%\left(<17 \mathrm{~kg} / \mathrm{m}^{2}\right)$ of values did not alter any of these odds ratios by $10 \%$ or more.

\section{The Association of Continuous BMI and PTD}

As shown in Fig. 2, the log odds of PTD as a function of continuous BMI from the LOESS smooth was V-shaped. Minimum risk of PTD occurred near the border of normal and overweight BMI categories, around $24 \mathrm{~kg} / \mathrm{m}^{2}$. Including subjects with BMI in the top $1 \%\left(>43 \mathrm{~kg} / \mathrm{m}^{2}\right)$ and bottom $1 \%\left(<17 \mathrm{~kg} / \mathrm{m}^{2}\right)$ of values in the LOESS analysis did not change the shape of the plot, but continued the linear increase in log odds as BMI increased above or decreased below $24 \mathrm{~kg} / \mathrm{m}^{2}$. The shape of the plot and position of the inflexion point were not altered by any of the following: exclusion of women who reported diabetes; adjustment for race; modeling White and Latina women separately; stratifying on parity; or stratifying PTDs into early preterm deliveries ( $n=144$; prior to 35 weeks gestation, range 21-34.5 weeks) and late preterm deliveries ( $n=200 ; 35-36$ weeks gestation) (data not shown).

For women with BMI $\leq 24 \mathrm{~kg} / \mathrm{m}^{2}$, each unit increase in $\mathrm{BMI}$ corresponded to reduced odds of PTD $(\beta=$ $-0.20,95 \% \mathrm{CI}=-0.31$ to $-0.09 ; \mathrm{AOR}=0.8195 \% \mathrm{CI}=$ 
Table 1 Characteristics of the study population, by case and control status a $P$-value derived from logistic regression model, adjusted for frequency matching by race and birth month

${ }^{b} P$-value not valid, as race was a frequency-matching variable

c Weight gain $=$ Total $\mathrm{kg}$ gained/Weeks Gestation Low $\leq 0.27 \mathrm{~kg} /$ week,

Adequate $=0.27-0.52 \mathrm{~kg} /$ week, High $\geq 0.52 \mathrm{~kg} /$ week) [17]

${ }^{\mathrm{d}}$ Underweight $\mathrm{BMI}<18.5$,

Normal BMI $=18.5$ to $<25$,

Overweight BMI $=25$ to $<30$,

Obese BMI $\geq 30$

\begin{tabular}{|c|c|c|c|c|c|}
\hline & \multicolumn{2}{|c|}{ PTD } & \multicolumn{2}{|c|}{ Controls } & \multirow[t]{2}{*}{$P^{\mathrm{a}}$} \\
\hline & $n$ & $\mathrm{Col} \%$ & $n$ & $\mathrm{Col} \%$ & \\
\hline \multicolumn{6}{|l|}{ Sociodemographic } \\
\hline Totals & 354 & 100 & 710 & 100 & \\
\hline \multicolumn{6}{|l|}{ Age } \\
\hline $18-25$ & 81 & 23 & 173 & 24 & 0.83 \\
\hline $26-33$ & 201 & 57 & 390 & 55 & \\
\hline $34+$ & 70 & 20 & 145 & 20 & \\
\hline \multicolumn{6}{|l|}{ Parity } \\
\hline Primiparous & 191 & 54 & 311 & 44 & 0.008 \\
\hline Multiparous & 163 & 46 & 399 & 56 & \\
\hline \multicolumn{6}{|l|}{ Race/Ethnicity } \\
\hline White & 159 & 45 & 297 & 42 & $\mathrm{NA}^{\mathrm{b}}$ \\
\hline Latina & 118 & 33 & 288 & 41 & \\
\hline Other & 77 & 22 & 125 & 18 & \\
\hline \multicolumn{6}{|l|}{ Marital status } \\
\hline Single & 39 & 11 & 60 & 8 & 0.08 \\
\hline Married/Cohabiting & 315 & 89 & 650 & 92 & \\
\hline \multicolumn{6}{|l|}{ Income } \\
\hline Low & 64 & 18 & 142 & 20 & 0.70 \\
\hline Middle & 105 & 30 & 213 & 30 & \\
\hline High & 183 & 52 & 352 & 50 & \\
\hline \multicolumn{6}{|l|}{ Education } \\
\hline No College & 102 & 29 & 239 & 34 & 0.95 \\
\hline Some college or beyond & 251 & 71 & 471 & 66 & \\
\hline \multicolumn{6}{|l|}{ Health } \\
\hline Any smoking during pregnancy & 9 & 3 & 26 & 4 & 0.47 \\
\hline Diabetes/High blood sugar & 56 & 16 & 62 & 9 & 0.002 \\
\hline$<6$ h sleep & 44 & 12 & 64 & 9 & 0.05 \\
\hline \multicolumn{6}{|l|}{ Psychosocial stress } \\
\hline None & 78 & 22 & 174 & 25 & 0.25 \\
\hline Low & 89 & 25 & 195 & 28 & \\
\hline Moderate & 87 & 25 & 164 & 23 & \\
\hline High & 99 & 28 & 175 & 25 & \\
\hline \multicolumn{6}{|l|}{ Height (tertiles) } \\
\hline$<1.58 \mathrm{M}$ & 118 & 33 & 227 & 32 & 0.44 \\
\hline $1.58-1.66 \mathrm{M}$ & 133 & 38 & 249 & 35 & \\
\hline$>1.66 \mathrm{M}$ & 103 & 29 & 234 & 33 & \\
\hline \multicolumn{6}{|l|}{ Weight gain during pregnancy ${ }^{c}$} \\
\hline Low & 88 & 25 & 145 & 21 & 0.004 \\
\hline Adequate & 179 & 51 & 425 & 60 & \\
\hline High & 86 & 24 & 136 & 19 & \\
\hline \multicolumn{6}{|l|}{$\mathrm{BMI}^{\mathrm{d}}$} \\
\hline Underweight & 22 & 6 & 24 & 3 & 0.05 \\
\hline Normal & 205 & 58 & 437 & 62 & \\
\hline Overweight & 72 & 20 & 158 & 22 & \\
\hline Obese & 55 & 16 & 91 & 13 & \\
\hline
\end{tabular}


Table 2 Odds ratios and 95\% confidence intervals for PTD as a function of categorized and continuous pre-pregnancy BMI

\begin{tabular}{|c|c|c|c|c|c|c|}
\hline & \multicolumn{3}{|c|}{ Design adjusted only } & \multicolumn{3}{|c|}{ Fully adjusted } \\
\hline & $n^{\mathrm{a}}$ & $\mathrm{OR}^{\mathrm{b}}$ & $95 \% \mathrm{CI}$ & $n$ & $\mathrm{AOR}^{\mathrm{b}, \mathrm{d}}$ & $95 \% \mathrm{CI}$ \\
\hline \multicolumn{7}{|l|}{$B M I$} \\
\hline \multicolumn{7}{|l|}{ Categorical } \\
\hline Underweight versus Normal & 1,042 & 1.99 & $0.99-4.01$ & 1,037 & 2.11 & $1.03-4.32$ \\
\hline Overweight versus Normal & & 1.08 & $0.78-1.51$ & & 1.07 & $0.76-1.51$ \\
\hline Obese versus Normal & & 1.42 & $0.96-2.11$ & & 1.31 & $0.86-2.00$ \\
\hline \multicolumn{7}{|l|}{ Continuous $^{\mathrm{c}}$} \\
\hline 17 versus 24 & 580 & 4.02 & $1.83-8.80$ & 578 & 4.31 & $1.94-9.54$ \\
\hline 19 versus 24 & & 2.70 & $1.54-4.73$ & & 2.84 & $1.61-5.01$ \\
\hline 29 versus 24 & 462 & 1.39 & $1.10-1.76$ & 459 & 1.42 & $1.10-1.84$ \\
\hline 34 versus 24 & & 1.95 & $1.22-3.11$ & & 2.01 & $1.20-3.39$ \\
\hline
\end{tabular}

${ }^{a}$ Highest and lowest $1 \%$ of BMI values excluded

b Adjusted for frequency matching by race and birth month

${ }^{\mathrm{c}}$ Odds ratios calculated from beta values of logistic models with a continuous linear BMI term

d Adjusted for parity, marital status, sleep, and weight gain during prgenancy

Fig. 2 Loess plot of log odds of PTD as a function of prepregnancy BMI. Equivalent odds ratios are indicated on vertical axis. Vertical lines indicate borders of IOM BMI categories as labeled

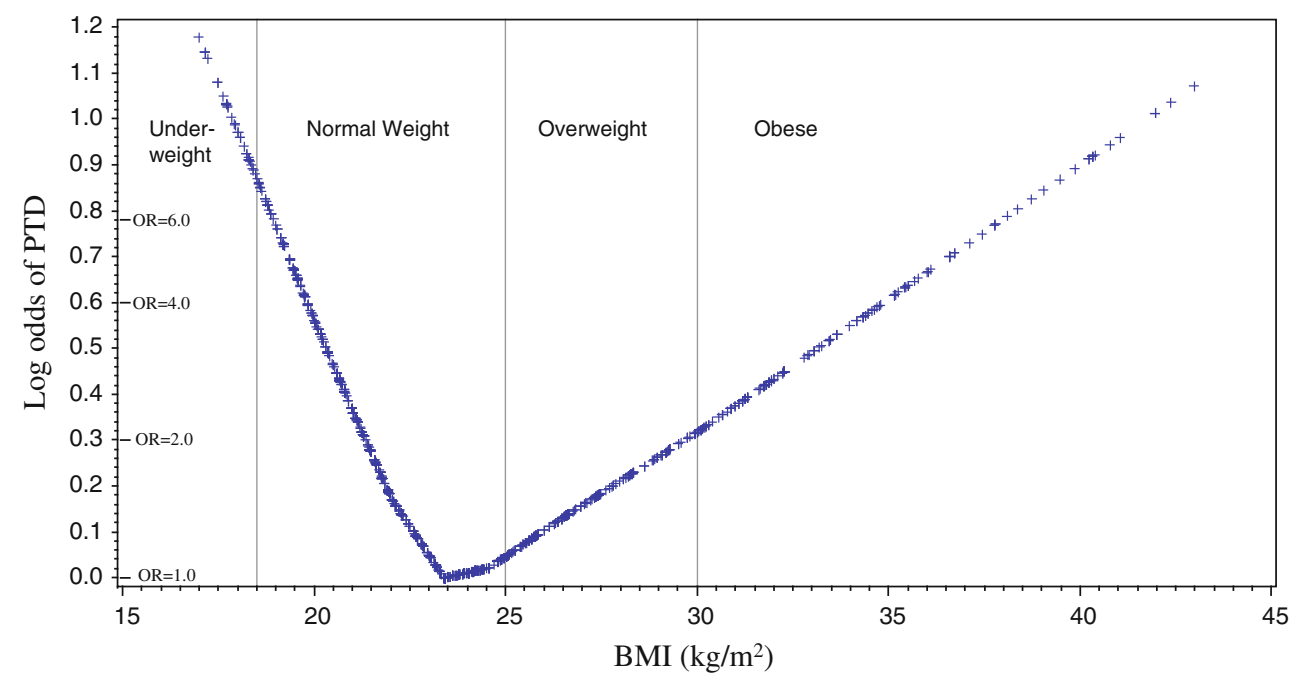

0.73-0.91), after adjustment for confounders (data not shown). Exclusion of subjects with diabetes or inclusion of subjects with BMI $<17$ did not alter the OR by $>10 \%$. As shown in Table 2, the model predicts that relative to a woman with a BMI of $24 \mathrm{~kg} / \mathrm{m}^{2}$, a woman with a BMI of $17 \mathrm{~kg} / \mathrm{m}^{2}$ (underweight) would have more than a fourfold increased odds of PTD (AOR $=4.3195 \% \mathrm{CI}=1.83-$ 8.80 ), and a woman with a BMI of $19 \mathrm{~kg} / \mathrm{m}^{2}$ (low normal) would have almost threefold elevated odds of PTD $(\mathrm{AOR}=2.8495 \% \mathrm{CI}=1.61-5.01)$.

Conversely, for women with BMI $>24 \mathrm{~kg} / \mathrm{m}^{2}$, the odds of PTD increased with increasing BMI $(\beta=0.07$, $95 \% \mathrm{CI}=0.02-0.12 ; \mathrm{AOR}=1.07,95 \% \mathrm{CI}=1.02-1.13)$. The model predicts that an overweight woman with a BMI of $29 \mathrm{~kg} / \mathrm{m}^{2}$, relative to a woman with a BMI of $24 \mathrm{~kg} / \mathrm{m}^{2}$, would have a $40 \%$ increased odds of PTD (AOR $=1.42$
$95 \% \mathrm{CI}=1.10-1.84)($ Table 2$)$. For an obese woman with a BMI of $34 \mathrm{~kg} / \mathrm{m}^{2}$, the odds relative to BMI of $24 \mathrm{~kg} / \mathrm{m}^{2}$ would be AOR $=2.01(95 \% \mathrm{CI}=1.20-3.39)$. Excluding women who reported diabetes during pregnancy did not alter the odds ratios by $>10 \%$ (data not shown). Inclusion of outlier BMI values $>43$ weakened the relationship, but the ORs at all BMI values remained significant (data not shown).

\section{Comparison of Categorical and Continuous BMI Models}

Figure 3 illustrates the predictions of the categorical and continuous models of BMI and shows that a more pronounced effect of both low and high BMI on PTD is apparent when using continuous BMI data. The steep 


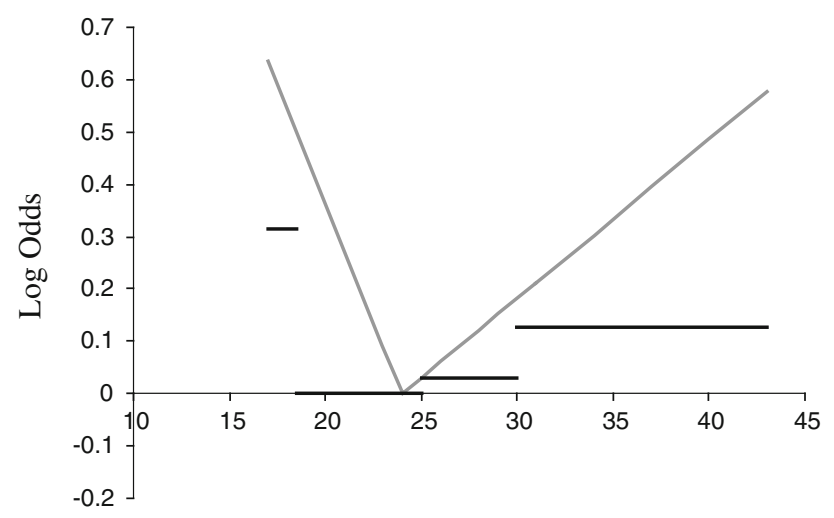

BMI $\left(\mathrm{kg} / \mathrm{m}^{2}\right)$

Log Odds of PTD predicted by categorical ( - ) and continuous $(-$ ) models of BMI.

Fig. 3 Log odds of PTD predicted by categorical (dark line) and continuous (gray line) models of BMI

increase in odds on the left side of the inflexion point in the continuous model demonstrates heterogeneity within the normal weight category. The categorical model uses the normal weight category as reference, with odds defined as 1.00 for this BMI range. Grouping together the very different odds within the normal weight range category $\left(18.5-25 \mathrm{~kg} / \mathrm{m}^{2}\right)$ inflates the odds of the reference group, resulting in a model that underestimates the increase in odds associated with both high and low BMI.

\section{Discussion}

Low and High Pre-pregnancy BMI Predict Increased Preterm Delivery

Our findings from a population of working women in Southern California indicate that PTD is independently associated with both low and high pre-pregnancy BMI. In addition to corroborating previous studies that found increased PTD risk among underweight women [19-21], we demonstrated a significant increase in PTD risk associated with high BMI. Our study found a protective effect of increased body mass up to $24 \mathrm{~kg} / \mathrm{m}^{2}$ and a detrimental effect beyond that point. In agreement with Simhan [22] and Gilboa [23], minimum PTD risk in this sample is associated with a pre-pregnancy BMI in the high normal/ low overweight range. Risk increases more steeply as BMI drops below $24 \mathrm{~kg} / \mathrm{m}^{2}$ than as it rises above $24 \mathrm{~kg} / \mathrm{m}^{2}$, so that a low normal BMI of $19 \mathrm{~kg} / \mathrm{m}^{2}$ is associated with a nearly threefold increase in PTD risk compared to high normal BMI of $24 \mathrm{~kg} / \mathrm{m}^{2}$, a higher risk than that associated with an obese BMI of $34 \mathrm{~kg} / \mathrm{m}^{2}$.

To our knowledge, this study is the first to find a significant PTD risk increasing continuously with rising BMI.
The previous study by Simhan et al. was restricted to spontaneous labors, which may account for the absence of a significant effect of high BMI in their results. In a study that examined spontaneous and indicated deliveries separately, Smith et al. concluded that overweight/obesity was protective with respect to spontaneous PTD, while increasing the risk of medically indicated PTD [24]. Although we cannot distinguish between spontaneous and indicated preterm births in our sample, it is plausible that the increased risk we observed with high BMI is due to medically indicated deliveries. Gilboa et al. also did not find elevated risk with high BMI, which may be due to small numbers of PTD cases in this range, estimation of gestational age based on LMP, or differences in the study population, which was restricted to White and Black women [23]. Our population was predominantly White and Latina, and while we saw similar results in White and Latina women, Simhan et al. found differences among Blacks, Latinas, and Whites. The question of whether and how ethnicity modifies the BMI-PTD relationship requires further study.

The observed shape of the BMI-PTD relationship was very similar for early and late $\mathrm{PTD}$, indicating that the association is not limited to PTD at a specific gestational age. Furthermore, we found that the higher risk associated with overweight/obesity persisted after adjustment for confounders, and across all race/ethnicities. The risk associated with pre-pregnancy BMI was independent of weight gain during pregnancy. These findings suggest a relationship between pre-pregnancy BMI and PTD that is robust.

The risk associated with high pre-pregnancy BMI was largely independent of diabetes, a common complication of pregnancy associated with obesity. Similar findings were reported by Baeten et al. [5] in a population-based cohort study of 96,801 birth certificates in Washington state in the 1990s, in so far as the increased risk of PTD associated with pre-pregnancy obesity remained after excluding women with pre-gestational or gestational diabetes or hypertension. This independence raises questions for future studies of whether the BMI-PTD relationship is mediated by unmeasured disease processes, or by endocrine changes in obese women during or prior to pregnancy.

PTD has been linked to inflammation [25, 26], which is increasingly seen as an important feature of obesity-related metabolic syndrome [27, 28]. Gene expression studies of non-pregnant humans have found increased levels of proinflammatory cytokines produced by fatty tissues of obese individuals [29-31]. These signaling molecules are also elevated in reproductive tissues just prior to term and preterm delivery, and are believed to play an important role in parturition [32-34]. Moreover, increased expression of pro-inflammatory cytokines and accumulation of 
macrophages has been found in the placenta of obese pregnant women [35]. Taken together, these observations suggest that further studies of pro-inflammatory cytokines during pregnancy might shed light on the association of obesity and PTD.

\section{Continuous Modeling of BMI Offers more Sensitive Risk Assessment}

We compared the results of two modeling approaches, one using the NHLBI/WHO categories, and the other treating BMI as a continuous function. The categorical model implicitly assumes that risk is constant across the normal weight category used as a reference; we found that this assumption was inaccurate, as in fact there was a nearly threefold increase in risk between the lower versus upper values of the normal BMI range. Grouping the normal BMI range together inflates the risk of the reference group thereby underestimating the increase in risk associated with both high and low BMI.

From a research standpoint, it is important to note that treating BMI according to NHLBI/WHO categories masked both the significant relationship of PTD to high BMI and the risk associated with low BMI within the "normal" range, and underestimated the risk associated with underweight. From a clinical perspective, our results suggest that the NHLBI/WHO categories, which were recently endorsed by the Institute of Medicine [36], may not be appropriate for identifying women at higher risk for PTD.

Use of a continuous model had several advantages over BMI categories. First, it required no assumption of constant risk within categories. The reference point was derived empirically from the data. Second, statistical power was increased [37]. Third, it closely approximated the V-shape of the risk function. This avoided creating the inaccurate impression of a threshold effect. Finally, it allowed comparison of risks at various points along the BMI continuum.

Our study has several limitations. We could not distinguish between spontaneous and medically indicated deliveries, and the etiology of these two types of PTD may be different. Our data on pre-pregnancy height, weight and weight gain were self-reported and therefore subject to error. However, self-reported pre-pregnancy weight has been shown to produce accurate BMI categories for most women [38], and correlated well with clinically measured weight at mid-pregnancy. We also had insufficient numbers of morbidly obese (BMI $>40)$ women $(n=23)$ to analyze the effects of morbid obesity separately. We had only selfreported data on diabetes. In addition, we lacked data on medication use. Furthermore, the sample may not be demographically representative of the general obstetric population, since not all pregnant women work and only
$45 \%$ of working women that were contacted met the work eligibility criteria. We sampled primarily Latina and White women; very few Black women were included, so our findings may not apply to this very high risk group. Future studies with larger populations are needed to address the effects of race, ethnicity, and induced versus spontaneous deliveries on the relationship between BMI and PTD.

Despite these caveats, the strengths of this study include a diverse three-county regional population, well-validated gestational age data, and an array of socio-demographic and health information, including weight gain during pregnancy. Our findings from continuous BMI models demonstrate a strong relationship between pre-pregnancy overweight/ obesity and PTD, as well as low normal BMI and PTD.

Pre-pregnancy BMI is a potentially modifiable risk factor affecting many pregnant women. This study does not form a basis for clinical recommendations to individual women; future studies considering multiple complications and outcomes of pregnancy are needed to address what advice should be given to women, particularly those whose BMI is low-normal, or low-overweight. Most importantly, interventions aimed at helping women achieve a healthy pre-pregnancy BMI must occur before pregnancy. Recent evidence suggests that people who received advice from a health care professional to lose weight are more likely to attempt weight loss [39], but few obese adults receive such advice during routine checkups [40, 41]. Workplaces, universities, urban planners, and policymakers also need to encourage good nutrition and exercise for women of reproductive age. Moreover, obesity often begins well before a woman enters her childbearing years. Therefore, an important implication of this work is that public health measures promoting nutrition and exercise among children and adolescents are likely to improve future obstetric outcomes.

Acknowledgments This work was funded in part by the Maternal and Child Health Bureau, division of research, training, and education, grant \#R40MV00305-01 to SG. This study was also partially funded by NIH grant \#R2MH081797, "Socioeconomic and Neuroendocrine Determinants of Perinatal Complications." We thank Maureen Lahiff and David Lein for helpful discussions of statistical analyses.

Open Access This article is distributed under the terms of the Creative Commons Attribution Noncommercial License which permits any noncommercial use, distribution, and reproduction in any medium, provided the original author(s) and source are credited.

\section{References}

1. Khashan, A. S., \& Kenny, L. C. (2009). The effects of maternal body mass index on pregnancy outcome. European Journal of Epidemiology, 24(11), 697-705.

2. Hendler, I., Goldenberg, R. L., Mercer, B. M., Iams, J. D., Meis, P. J., Moawad, A. H., et al. (2005). The preterm prediction study: 
Association between maternal body mass index and spontaneous and indicated preterm birth. American Journal of Obstetrics and Gynecology, 192(3), 882-886.

3. Kramer, M. S., Coates, A. L., Michoud, M. C., Dagenais, S., Hamilton, E. F., \& Papageorgiou, A. (1995). Maternal anthropometry and idiopathic preterm labor. Obstetrics and Gynecology, 86(5), 744-748.

4. Cnattingius, S., Bergstrom, R., Lipworth, L., \& Kramer, M. S. (1998). Prepregnancy weight and the risk of adverse pregnancy outcomes. New England Journal of Medicine, 338(3), 147-152.

5. Baeten, J. M., Bukusi, E. A., \& Lambe, M. (2001). Pregnancy complications and outcomes among overweight and obese nulliparous women. American Journal of Public Health, 91(3), 436-440.

6. Weiss, J. L., Malone, F. D., Emig, D., Ball, R. H., Nyberg, D. A., Comstock, C. H., et al. (2004). Obesity, obstetric complications and cesarean delivery rate-a population-based screening study. American Journal of Obstetrics and Gynecology, 190(4), 1091-1097.

7. Sebire, N. J., Jolly, M., Harris, J. P., Wadsworth, J., Joffe, M., Beard, R. W., et al. (2001). Maternal obesity and pregnancy outcome: A study of 287, 213 pregnancies in London. International Journal of Obesity and Related Metabolic Disorder, 25(8), 1175-1182.

8. Kumari, A. S. (2001). Pregnancy outcome in women with morbid obesity. International Journal of Gynaecology and Obstetrics, 73(2), 101-107.

9. National Heart Lung and Blood Institute (NHLBI). (1998). Clinical guidelines on the identification, evaluation, and treatment of overweight and obesity in adults. National Heart Lung and Blood Institute (NHLBI).

10. World Health Organization. (1998). Obesity_Preventing and managing the global epidemic. World Health Organization.

11. WHO. (1995). Physical status: The use and interpretation of anthropometry. Report of a WHO Expert Committee. Geneva: World Health Organization.

12. Guendelman, S., Kosa, J. L., Pearl, M., Graham, S., Goodman, J., \& Kharrazi, M. (2009). Juggling work and breastfeeding: Effects of maternity leave and occupational characteristics. Pediatrics, 123(1), e38-e46.

13. Guendelman, S., Pearl, M., Graham, S., Angulo, V., \& Kharrazi, M. (2006). Utilization of pay-in antenatal leave among working women in Southern California. Maternal and Child Health Journal, 10(1), 63-73.

14. Dietz, P. M., England, L. J., Callaghan, W. M., Pearl, M., Wier, M. L., \& Kharrazi, M. (2007). A comparison of LMP-based and ultrasound-based estimates of gestational age using linked California livebirth and prenatal screening records. Paediatric and Perinatal Epidemiology, 21(Suppl 2), 62-71.

15. Pearl, M., Wier, M. L., \& Kharrazi, M. (2007). Assessing the quality of last menstrual period date on California birth records. Paediatric and Perinatal Epidemiology, 21(Suppl 2), 50-61.

16. Lobel, M., Dunkel-Schetter, C., \& Scrimshaw, S. C. (1992). Prenatal maternal stress and prematurity: A prospective study of socioeconomically disadvantaged women. Health Psychology, 11(1), 32-40.

17. Abrams, B., Newman, V., Key, T., \& Parker, J. (1989). Maternal weight gain and preterm delivery. Obstetrics and Gynecology, 74(4), 577-583.

18. Cleveland, W. S. (1979). Robust locally weighted regression and smoothing scatterplots. Journal of the American Statistical Association, 74(368), 829-836.

19. Siega-Riz, A. M., Adair, L. S., \& Hobel, C. J. (1996). Maternal underweight status and inadequate rate of weight gain during the third trimester of pregnancy increases the risk of preterm delivery. Journal of Nutrition, 126(1), 146-153.
20. Salihu, H. M., Mbah, A. K., Alio, A. P., Clayton, H. B., \& Lynch, O. (2009). Low pre-pregnancy body mass index and risk of medically indicated versus spontaneous preterm singleton birth. European Journal of Obstetrics, Gynecology, and Reproductive Biology, 144(2), 119-123.

21. Hauger, M. S., Gibbons, L., Vik, T., \& Belizan, J. M. (2008). Prepregnancy weight status and the risk of adverse pregnancy outcome. Acta Obstetricia et Gynecologica Scandinavica, 87(9), 953-959.

22. Simhan, H. N., \& Bodnar, L. M. (2006). Prepregnancy body mass index, vaginal inflammation, and the racial disparity in preterm birth. American Journal of Epidemiology, 163(5), 459-466.

23. Gilboa, S. M., Correa, A., \& Alverson, C. J. (2008). Use of spline regression in an analysis of maternal prepregnancy body mass index and adverse birth outcomes: Does it tell us more than we already know? Annals of Epidemiology, 18(3), 196-205.

24. Smith, G. C., Shah, I., Pell, J. P., Crossley, J. A., \& Dobbie, R. (2007). Maternal obesity in early pregnancy and risk of spontaneous and elective preterm deliveries: A retrospective cohort study. American Journal of Public Health, 97(1), 157-162.

25. Romero, R., Espinoza, J., Goncalves, L. F., Kusanovic, J. P., Friel, L., \& Hassan, S. (2007). The role of inflammation and infection in preterm birth. Seminars in Reproductive Endocrinology, 25(1), 21-39.

26. Goldenberg, R. L., Hauth, J. C., \& Andrews, W. W. (2000). Intrauterine infection and preterm delivery. New England Journal of Medicine, 342(20), 1500-1507.

27. Bastard, J. P., Maachi, M., Lagathu, C., Kim, M. J., Caron, M., Vidal, H., et al. (2006). Recent advances in the relationship between obesity, inflammation, and insulin resistance. European Cytokine Network, 17(1), 4-12.

28. Jiamsripong, P., Mookadam, M., Honda, T., Khandheria, B. K., \& Mookadam, F. (2008). The metabolic syndrome and cardiovascular disease: Part I. Preventive Cardiology, 11(3), 155-161.

29. Lee, Y. H., Nair, S., Rousseau, E., Allison, D. B., Page, G. P., Tataranni, P. A., et al. (2005). Microarray profiling of isolated abdominal subcutaneous adipocytes from obese vs non-obese Pima Indians: Increased expression of inflammation-related genes. Diabetologia, 48(9), 1776-1783.

30. Nair, S., Lee, Y. H., Rousseau, E., Cam, M., Tataranni, P. A., Baier, L. J., et al. (2005). Increased expression of inflammationrelated genes in cultured preadipocytes/stromal vascular cells from obese compared with non-obese Pima Indians. Diabetologia, 48(9), 1784-1788.

31. Shynlova, O., Tsui, P., Dorogin, A., \& Lye, S. J. (2008). Monocyte chemoattractant protein-1 (CCL-2) integrates mechanical and endocrine signals that mediate term and preterm labor. Journal of Immunology, 181(2), 1470-1479.

32. Keelan, J. A., Blumenstein, M., Helliwell, R. J., Sato, T. A., Marvin, K. W., \& Mitchell, M. D. (2003). Cytokines, prostaglandins and parturition-a review. Placenta, 24(Suppl A), S33-S46.

33. Thomson, A. J., Telfer, J. F., Young, A., Campbell, S., Stewart, C. J., Cameron, I. T., et al. (1999). Leukocytes infiltrate the myometrium during human parturition: Further evidence that labour is an inflammatory process. Human Reproduction, 14(1), 229-236.

34. Osman, I., Young, A., Ledingham, M. A., Thomson, A. J., Jordan, F., Greer, I. A., et al. (2003). Leukocyte density and proinflammatory cytokine expression in human fetal membranes, decidua, cervix and myometrium before and during labour at term. Molecular Human Reproduction, 9(1), 41-45.

35. Challier, J. C., Basu, S., Bintein, T., Minium, J., Hotmire, K., Catalano, P. M., et al. (2008). Obesity in pregnancy stimulates macrophage accumulation and inflammation in the placenta. Placenta, 29(3), 274-281. 
36. Institute of Medicine. (2009). Weight gain during pregnancy: Re-examining the guidelines. Washington DC: Institute of Medicine.

37. Selvin, S. (1995). Practical biostatistical methods. Belmont, CA: Duxbury Press.

38. Craig, B. M., \& Adams, A. K. (2009). Accuracy of body mass index categories based on self-reported height and weight among women in the United States. Maternal and Child Health Journal, 13(4), 489-496.

39. Galuska, D. A., Will, J. C., Serdula, M. K., \& Ford, E. S. (1999). Are health care professionals advising obese patients to lose weight? JAMA, 282(16), 1576-1578.
40. Shiffman, S., Sweeney, C. T., Pillitteri, J. L., Sembower, M. A., Harkins, A. M., \& Wadden, T. A. (2009). Weight management advice: What do doctors recommend to their patients? Preventive Medicine, 49(6), 482-486.

41. Power, M. L., Cogswell, M. E., \& Schulkin, J. (2006). Obesity prevention and treatment practices of US obstetriciangynecologists. Obstetrics and Gynecology, 108(4), 961-968. 